\title{
The use of biomarkers in clinical osteoporosis
}

\author{
Hebert Wilson Santos Cabral ${ }^{1 *}$, Bruna Ferreira Galone Andolphi², Brunna Vila Coutinho Ferreira², \\ Danielle Cristina Filgueira Alves² ${ }^{2}$ Renato Lírio Morelato ${ }^{3}$, Antônio Chambo Filho ${ }^{4}$, LizÂnia Spinassé Borges 5

Study conducted at Escola Superior de Ciências da Santa Casa de Misericórdia de Vitória (Emescam), Vitória, ES, Brazil

Article received: $12 / 18 / 2014$ Accepted for publication: 3/23/2015

*Correspondence: Address: Av. Nossa Senhora da Penha, 2190, Bela Vista Vitória, ES - Brazil Postal code: $29027-502$ sme@smeconsultoria.com.br

\section{SUMmARY}

Osteoporosis is a disease of ascending character in the world population; in this context, bone biomarkers are being increasingly studied in order to aid in the diagnosis and monitoring of these patients. The main objective of this study was a literature review of articles whose main theme was the use of biomarkers for bone formation and degradation, and to evaluate their possible applicability in clinical practice. Literature review was performed through articles indexed and published in the last five years in the PubMed database. The findings of this study showed that most of the previously selected articles were published in the last two years, and the most cited markers were bone resorption, C-terminal collagen telopeptide (CTX), showing the highest correlation with the dynamics of bone, and the biomarker of bone formation, bone-specific alkaline phosphatase (BAP), which is increased in the event of fracture or may suggest another bone disease. There was an increase in published articles, associating different bone biomarkers and their clinical applicability, especially for treatment control. Our findings suggest that in recent years there has been significant increase in publications evaluating the use of bone turnover biomarkers for bone formation and resorption and their possible clinical applicability, especially in the monitoring of treatment. Still, we believe that further studies need to be conducted to confirm these findings, given the advantages that bone biomarkers can deliver in the clinical management of the disease.

Keywords: osteoporosis, bone remodeling, biological markers.

\section{INTRODUCTION}

Osteoporosis (OP) is a systemic disease characterized by decreased bone mass and microstructural deterioration of bone tissue, with consequent increase of fragility and susceptibility to fracture. ${ }^{1}$ Most of the fractures caused by osteoporosis have considerable impact on economically active individuals, and there is a substantial risk of increased mortality and mobility in the elderly population, interfering directly in the quality of life. ${ }^{2}$ Ethnic, genetic, anthropometric, socio-cultural and economic difference and other life habits contribute to explaining the differences in the incidence and prevalence of osteoporosis. ${ }^{3,6}$
According to data from the World Health Organization (WHO), OP affects more than 75 million people in the United States (USA), Europe and Japan, accounting for more than 8.9 million fractures annually around the world, with more than 4.5 million occurring in the Americas and Europe. ${ }^{4}$ In Brazil, osteoporosis is estimated to affect 10 million people, with a prevalence of 11 to $23.8 \%$ for all types of bone fracture. ${ }^{3}$ According to the Ministry of Health, in the year 2007 around BRL 51.8 million was spent on hospitalizations, and each year spending arising from the treatment of fractures increases, especially in elderly people. ${ }^{5}$

Data from the literature suggest that there are several effective treatments. However, the drugs that proved to be 
effective in preventing fractures, thus being approved for the treatment of OP, are bisphosphonates (alendronate, risedronate and ibandronate), categorized as bone antiresorptive medication and remaining the most popular and widely used pharmacological treatment for osteoporosis. However, when these drugs are contraindicated or cause serious side effects, new treatments and alternative pharmacological forms are available. Currently, there has been a great difficulty in assessing response to treatment, since Bone Densitometry (DXA), considered the gold standard in both the diagnosis and monitoring of these patients, is a diagnostic method not often available in basic health services. ${ }^{7}$ The latest data from the literature has been suggesting an alternative to the use of DXA in the clinical monitoring of OP patients: biomarkers of bone resorption and formation. Bone remodeling can be easily measured using a variety of biochemical markers, which are largely divided into two categories: markers of bone resorption, which reflect the activity of osteoclasts, are mostly the products of type 1 collagen degradation; and markers of bone formation, reflecting the activity of osteoblasts and are the byproducts of collagen synthesis (matrix proteins or osteoblastic enzymes). The main markers of bone formation in the blood are: a) osteocalcin (bone Gla-protein) - OC, b) total alkaline phosphatase (ALP), c) procollagen type 1 carboxy-terminal propeptide, and d) procollagen 1 amino-terminal propeptide (P1NP). Bone resorption and bone formation processes are coupled, so in some situations these markers will reflect on the changes in bone remodeling. ${ }^{2}$ Bone resorption markers in the blood are: a) tartrate-resistant acid phosphatase (TRACP), b) procollagen type $1 \mathrm{c}$ terminal portion (S-CTX). Bone resorption markers found in urine include: a) Pyridinoline and deoxypyridinoline (UPYD and DPD-U), b) hydroxyproline (U-HYP), c) aminoterminal portion of procollagen I (U-NTX), d) carboxy-terminal portion of procollagen I (U-CTX). ${ }^{26}$

The dosage of these biomarkers would be another useful tool in monitoring therapy for this pathology. While DXA would be evidence of a positive response to treatment with increased bone mineral density (BMD), 1 to 2 years after the increase of formation biomarkers, a reduction of those related to bone resorption could be detected 3 to 6 months after the drug intervention. Recent studies have shown limitations on the use of biomarkers of bone resorption, suggesting that more studies need to be conducted for their application in routine clinical practice. ${ }^{8}$

\section{Method}

The present study is a review of the literature using articles published over the last five years and stored in a sci- entific database. The main objective was to determine the clinical applicability of bone biomarkers over the years and nowadays, as described in the flowchart (Figure 1).

\section{Selection and searching of articles by keywords}

In order to define the descriptors to be used in the research, searches were carried out on the PubMed website (US Library of Medicine) using the keywords: "biomarker osteoporosis", and the following filters: review papers, completed text in descending order based on date of publication. According to our search the most cited descriptors were: a) bone mineral density osteoporosis, b) biochemical bone markers, c) bone turnover, d) osteometabolic diseases, e) osteoporosis, f) bone formation and resorption markers.

The search was distributed to three researchers, in such a way that the findings relating to the first three mentioned descriptors were evaluated by Researcher A, the two following descriptors by Researcher $\mathrm{B}$ and the last two by Researcher $C$ (Figure 1). The exclusion criteria were defined as: a) review articles that only cited the biomarkers, but did not discuss their applicability in the clinical practice, b) articles whose main theme did not include biomarkers in osteoporosis. Thus, the inclusion criteria were: a) the articles that discussed the clinical use of biomarkers in osteoporosis and presented evidence in the occurrence of clinical conditions associated with the disease. Our last search of the database was performed in December 2014.

\section{Data collection}

Data collection was carried out over a period of 12 months, during which the information extracted from articles previously selected was: a) names of the biomarkers analyzed in publications, b) classification of biomarkers as to their role in the bone metabolism phase, c) date of publication of the article, d) number of authors, e) sample size and period of study. After the selection of articles published over the last five years, they were stratified and divided into two groups: publications made over the past two and a half years and articles published more than two and a half years ago. The number of authors was also grouped into two categories: up to three authors and more than three authors. We noted that the number of participants was described in variable and continuous manner. Study duration in the articles was divided into four groups: up to 1 year; 2 to 5 years; 5 to 10 years and more than 10 years.

The entire data was tabulated in a database for further evaluation of a possible clinical applicability. 


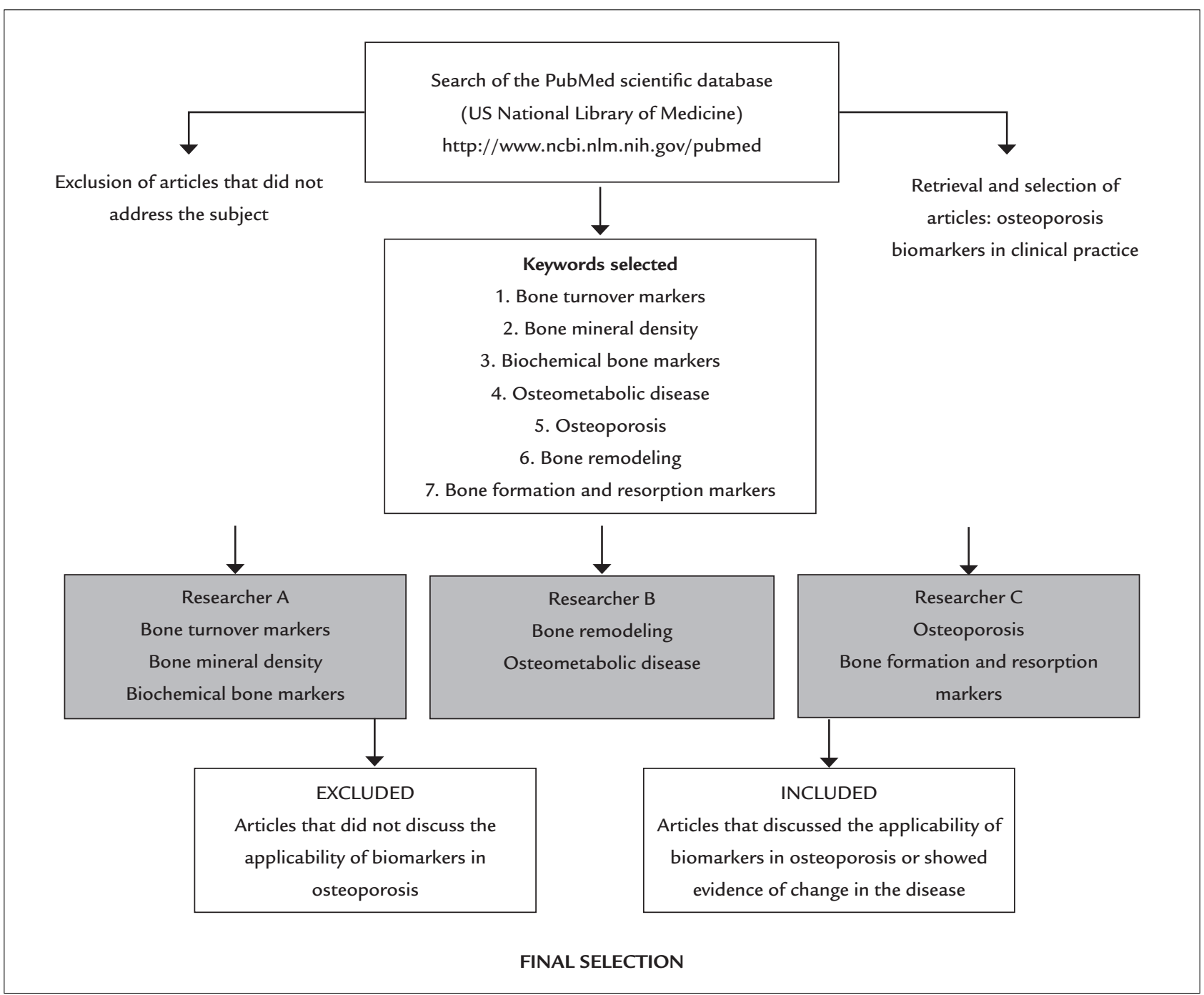

FIGURE 1 Flowchart for selection of scientific articles.

\section{Identification and classification of biomarkers}

Bone markers were listed according to their description in the articles as per the corresponding classification. The classification regarding type of biomarkers evaluated in the clinical trials was divided into the following groups: i) Formation biomarkers: These are represented by enzymes or products that participate in the genesis of the bone matrix and function as bone formation markers if dosed; ${ }^{9}$ ii) Degradation biomarkers: classified as proteins or their fragments released during formation of the bone degradation process, which when dosed have the function of bone resorption markers. ${ }^{10}$ We noted that both markers were cited in the same article and that other types of biomarkers used were not appropriate for classification in our study, that is, were not considered as bone formation or degradation biomarkers. Biomarkers classified as associated in scientific publications address one or more bio- markers, named as "others" in this study, and were added to the dosage of bone resorption formation markers.

\section{Data analysis}

For data analysis, we used descriptive statistics in order to summarize data into: i) Number, ii) simple frequencies, iii) mean and standard deviations, and iv) construction of tables. The data was processed using chi-squared test to compare simple frequencies and Student's t test to compare averages of the parameters. The Statistical Package for Social Science for Windows (SPSS) 17 software was used in all statistical analyses, adopt $\mathrm{p}<0.05$ and a confidence level of $95 \%$.

\section{Results}

Following the methodology described in the present study, in our results we examined 7,996 articles relating to the 
descriptors "osteoporosis", 2,729 "bone formation" and 152 "resorption markers", 7 "osteometabolic diseases", 1,788 "bone remodelling", 1,753 "bone turnover markers", 172 "biochemical bone markers", 1,395 "bone mineral density". 66 articles were considered eligible for this study and were categorized according to the type of biomarker: Bone formation and bone degradation, both of which were cited in the references used. We also noted other biomarkers, but they did not apply to the classification used in our target of study. Our findings show that the data from the literature classifies some biomarkers with the associated term, covering formation and degradation biomarkers along with non-classifiable ones, as can be observed in Table 1. According to this table, we see that more than $50 \%$ of the articles discuss formation and degradation biomarkers in conjunction. On the other hand, analyses of non-classifiable biomarkers were observed at a rate of $7.6 \%$, when analyzed in isolation, and $6.1 \%$ in association with formation and degradation markers. The chi-squared statistical tests showed significance at a p-value $<0.05$ but the number of biomarkers defined as "others" and "associated" was low, and this result should be evaluated carefully. Nevertheless, this demonstrates greater significance compared with the data observed in the clinical trials, which address bone formation and degradation biomarkers concomitantly.

TABLE 1 Number and percentage of selected articles that discuss the subject of osteoporosis biomarkers.

\begin{tabular}{lll} 
Type of marker & Frequency & Percentage (\%) \\
\hline Formation $^{\mathrm{a}}$ & 9 & 13.6 \\
\hline Degradation $^{\mathrm{b}}$ & 13 & 19.7 \\
\hline Both $^{\mathrm{c}}$ & 35 & 53.0 \\
\hline Other $^{\mathrm{d}}$ & 5 & 7.6 \\
\hline Associated & & 6.1 \\
\hline Total & 4 & 100 \\
\hline
\end{tabular}

aSubstances present in the genesis of bone matrix; 'substances released during the process of bone degradation; ' formation and degradation biomarkers cited in the same article; 'biomarkers that are not categorized as formation or degradation; ' ${ }^{\mathrm{C}}$ citations of formation and degradation biomarkers along with non-classifiable ones (others).

Main types of biomarkers cited in the selected articles and their clinical applicability

In the texts retrieved, we found 13 different types of biomarkers: a) BAP (bone alkaline phosphatase), b) OPG (osteoprotegerin), c) RANKL (nuclear factor Kappa E), d) P1CP (type 1 procollagen carboxy-terminal propeptide), e) P1NP (amino-terminal propeptide) f) OC (Osteocalcin), g) TRACP (tartrate-resistant acid phosphatase), h) TNF-alpha (tumor necrosis factor-alpha), i) PYD (pyridinoline), j) DPD (deoxypyridinoline), k) CTX (carboxy-terminal telopeptide of type 1 collagen), l) NTX (amino-terminal telopeptide of type 1 collagen), m) ALP (serum alkaline phosphatase). These are shown in Chart 1 , which represents the total frequency of citations of the biomarkers and their applicability in a more generalized form. Note that the biomarkers cited the most were P1NP (procollagen 1 amino-terminal propeptide), BAP of bone formation and CTX of bone degradation. It is important to note that a considerable number of each biomarker has confirmed clinical applicability; for example, we can mention the degradation biomarker CTX, observed in 35 citations with applicability confirmed by 25 of them. In relation to formation biomarkers, P1NP was cited in 25 clinical trials demonstrating clinical application in 18 citations.

\section{Evolution of the percentage of papers published in the last five years}

Evaluating all of the selected works, we found that approximately $57.8 \%$ were published in the last five years. The period observed was from April 2011 to March 2012, where there was a large increase in the number of publications in scientific databases. However, a reduction of publications was noted in the periods between April 2010 and March 2011. This data is displayed in Chart 2.

As for types of biomarkers, the increased variability studied is well-known, given that in studies published between April 2008 and March 2009, there are just two sub-types of articles, that is, those addressing formation biomarkers only, and those covering formation and degradation biomarkers together, whereas in the publications in the period between April 2012 and April 2013, five subtypes were analyzed, that is, formation biomarkers, degradation biomarkers, both, others and associated biomarkers.

\section{Average number of participants studied in the selected articles} A variable number of participants were evaluated. The largest study included 9,846 individuals and the smallest study had only eight participants. Publications that used the term biomarkers classified as "both" had the highest average participants, with 713.46 , but also the highest standard deviation $(1,824.63)$. Meanwhile, articles covering the "associated" biomarkers category obtained the lowest values for the mean and standard deviation, 44 and 29.73, respectively. Our statistical analysis using Student's t-test for comparison of the averages showed statistical significance. However, due to high sampling variability, there was a high standard deviation in some variables, suggesting a strong probability that the distri- 


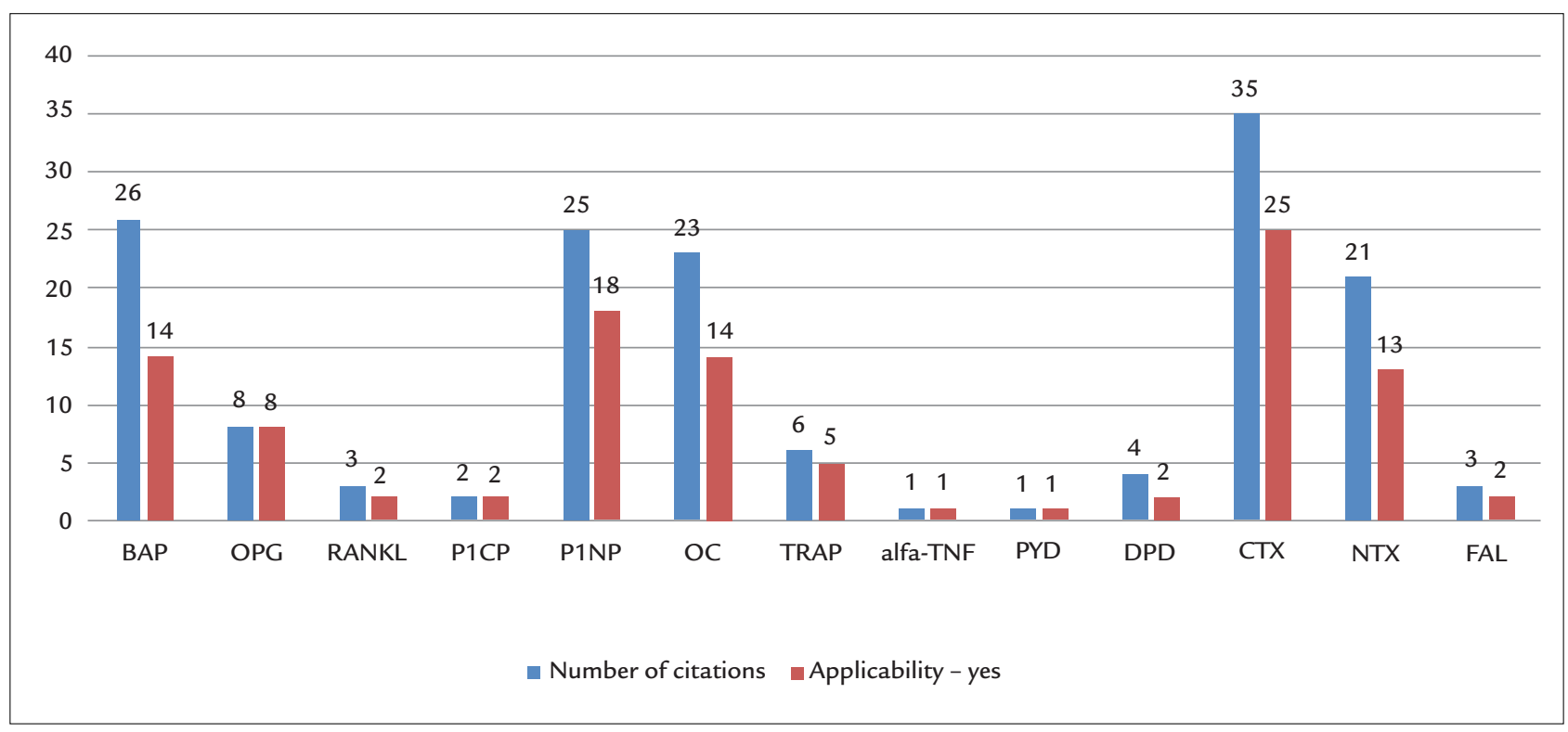

CHART 1 Types of bone biomarkers and their medical applicability.

BAP: bone alkaline phosphatase; OPG: osteoprotegerin; RANKL: receptor activator of nuclear factor kappa-E; P1CP: carboxy-terminal propeptide of type 1 procollagen; P1NP: amino-terminal propeptide; OC: osteocalcin; TRACP: tartrate-resistant acid phosphatase; TNF-alpha: tumor necrosis factor-alpha; PYD: pyridinoline; DPD: deoxypyridinoline; CTX: carboxy-terminal telopeptide of type 1 collagen; NTX: amino-terminal telopeptide of type 1 collagen; ALP: serum alkaline phosphatase.

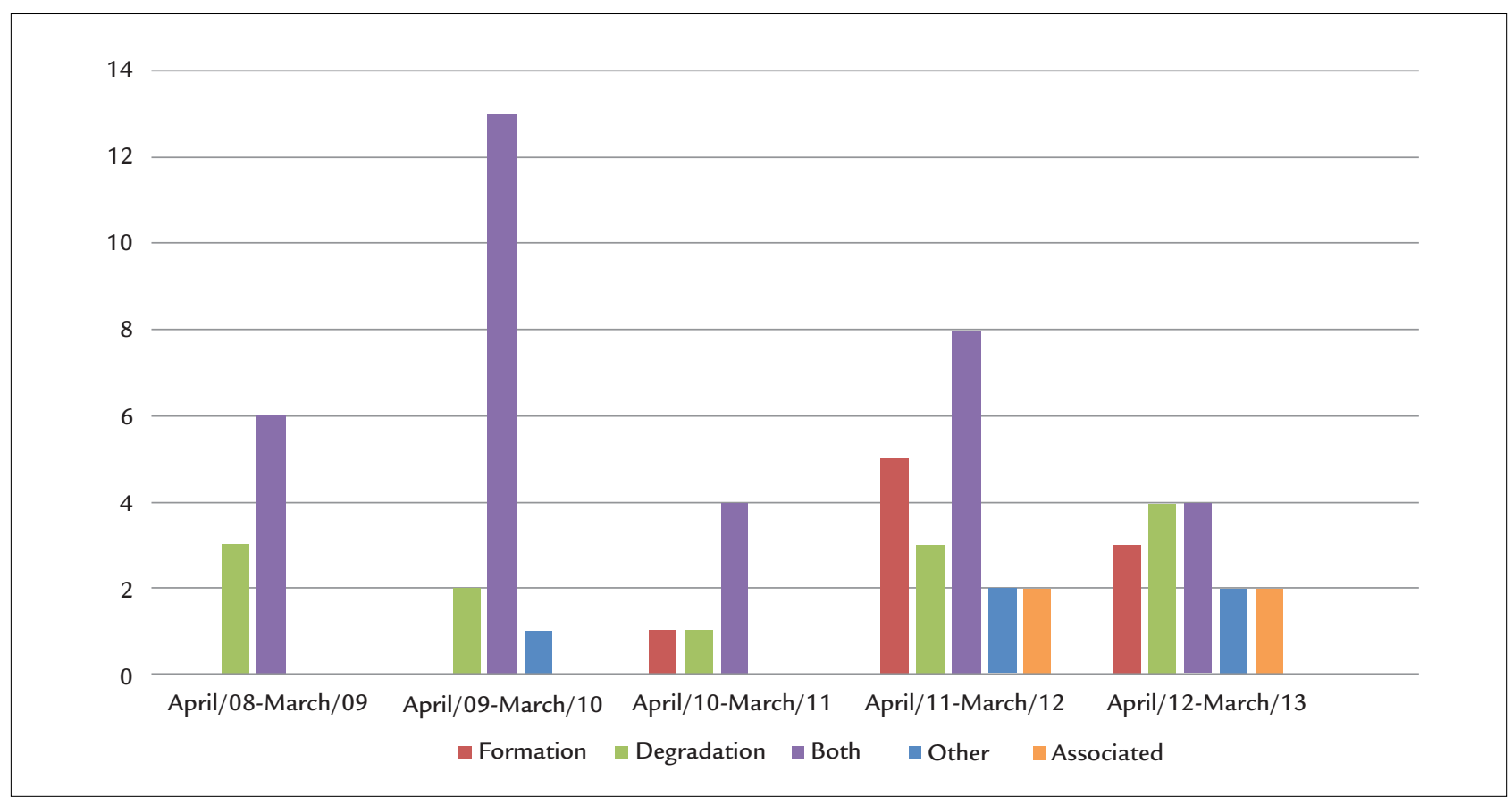

CHART 2 Analysis of the number of studies grouped by type of biomarker, published in the period.

Formation: substances present in the genesis of bone matrix; degradation: substances released during the process of bone degradation; both: formation and degradation biomarkers cited in the same article; other: citations of biomarkers that are not categorized as formation or degradation; associated: citations of formation and degradation biomarkers along with non-classifiable ones (others). 
butions do not assume normality, showing that employing Student's t-test as method was not the best choice, and suggesting that the results between the comparisons should be made using nonparametric tests in this kind of analysis.

\section{Duration of patient monitoring in the selected articles}

During the period of study, patients remained similar, meaning that $31.8 \%$ of the studies lasted from two to five years. It is important to note that $30.3 \%$ of the articles did not report the assessment period precisely, representing a selection bias in this evaluation. Regarding patient monitoring, we did not find long-term studies, with those conducted for more than 6 years representing only $9.1 \%$ of the sample. We performed some multiple comparisons through chi-square test, showing significance $(\mathrm{p}<0.05)$ between some of the items observed, but since some sub-items were represented by zero and numbers less than five, the chi-squared test cannot be considered valid.

Clinical applicability of the use of biomarkers in the selected articles

Of the articles selected and indexed, approximately 80.3\% showed any clinical applicability of the biomarkers with statistical significance $(\mathrm{p}<0.001)$. During our analysis, subdividing the items in the 66 articles, the comparisons were limited by chi-squared test for the reasons mentioned above. Observing Table 2 again, we can see that the biomarkers allocated as "others" and "associated" and cited in smaller numbers obtained $100 \%$ clinical applicability, while in the group defined as "both", present in a greater number of publications, there was $77.1 \%$ applicability, both following an overall trend in the study. When conducting an individual analysis of the biomarkers, we noted that P1CP (carboxy-terminal propeptide of type 1 procollagen) presented $100 \%$ applicability, but was only cited in two references. BAP has a higher frequency in the citations, with a clinical applicability confirmed in $54 \%$ of the publications analyzed. By analyzing PYD (Pyridinoline), a degradation biomarker, applicability was confirmed despite the fact that this marker was reviewed only in one article, while CTX, cited the most in the references, and showed $71 \%$ of possible use. OPG (Osteoprotegerin), cited most often within the group of non-classifiable biomarkers, presented $100 \%$ applicability for clinical use. The results with TNF- $\alpha$ and RANKL (receptor activator of nuclear factor kappa-E) should be analyzed and interpreted with a larger sample size for confirmation of their actual application.
TABLE 2 Applicability in the articles according to the type of biomarker.

\begin{tabular}{lllll} 
Applicability & Yes & \multicolumn{3}{l}{ No } \\
\hline Biomarkers & $\begin{array}{l}\text { Number } \\
(\mathbf{n = 5 3 )}\end{array}$ & $\begin{array}{l}\text { Frequency } \\
\mathbf{\%}\end{array}$ & $\begin{array}{l}\text { Number } \\
(\mathbf{n = 1 3 )}\end{array}$ & Frequency \\
\hline Formation $^{\mathrm{a}}$ & 8 & 88.9 & 1 & 11.1 \\
\hline Degradation $^{\mathrm{b}}$ & 9 & 69.2 & 4 & 30.8 \\
\hline Both $^{\mathrm{c}}$ & 27 & 77.1 & 8 & 22.9 \\
\hline Other $^{\mathrm{d}}$ & 5 & 100 & 0 & 0 \\
\hline Associated $^{\mathrm{e}}$ & 4 & 100 & 0 & 0
\end{tabular}

aSubstances present in the genesis of bone matrix; 'bsubstances released during the process of bone degradation; ' formation and degradation biomarkers cited in the same article; dbiomarkers that are not categorized as formation or degradation; ${ }^{\mathrm{C}}$ citations of formation and degradation biomarkers along with non-classifiable ones (others).

\section{Discussion}

Bone turnover biomarkers have contributed to a better understanding of the physiology of bones as well as the pathogenesis of metabolic bone diseases. In recent years, several technologies have been developed in order to determine markers in osteoporosis. Our study looked at 66 articles over the last five years. During this period we observed a predominance of references that addressed both formation and degradation marker, with around $53 \%$ of citations mentioning both. This fact may be attributed to prior knowledge involving bone formation and degradation that are bound and dependent. It is believed that these processes need to be analyzed in conjunction in order to evaluate bone metabolism in a more suitable manner. ${ }^{11}$ The most relevant findings of the selected publications are based on the application of biomarkers with the purpose of monitoring the treatment of osteoporosis. ${ }^{12}$ The findings in the study by Grey et al. suggest that bone metabolism markers were low in $40 \%$ of patients undergoing treatment with zoledronate compared to a placebo group. ${ }^{12}$ Teriparatide, an osteoanabolic drug for the treatment of osteoporosis, was also used often. Studies conducted recently suggest that this drug may be effective to speed up the healing of fractures, as well as to stimulate the process in patients with delayed healing. ${ }^{13}$ According to Jakob et al. this corroborates previous observations when concluding that women after menopause diagnosed with severe osteoporosis benefited from the use of teriparatide even with the interruption of therapy 18 months beforehand. ${ }^{14}$

We observed that the most prevalent formation biomarkers were P1NP (procollagen 1 amino-terminal propeptide) and BAP, while CTX was applied the greatest number of times among resorption biomarkers. A concordance with the current literature was noted in these 
findings, as a document recently released by the Bone Marker Standards Working Group, in conjunction with the International Osteoporosis Foundation (IOF) and the International Federation of Clinical Chemistry and Laboratory Medicine (IFCC), suggested the use of bone formation and resorption markers in clinical trials, such as P1NP (formation marker) and CTX (resorption marker). ${ }^{15}$ In view of the difficulty of establishing an ideal marker, the reference standards were chosen based on criteria such as adequate characterization and definition of each marker in relation to specificity to the bone, the results observed in clinical trials, biological variability, ease for analyzing the data, the availability of the method in analysis laboratories, and the means of measuring the biological sample (serum or urine). ${ }^{16}$

In the last five years, around $57.6 \%$ of the articles were published in the period from 2011 to 2014, i.e. over the last 3.5 years. Our observational data suggest a gradual increase in the number of publications about this subject, justified by increasing advances in research on isolation and characterization of cells and studies on extracellular components of the bone matrix, resulting in the development and implementation of new technologies for serum or urinary measurement of new biochemical markers of bone metabolism. ${ }^{17}$ Advances in molecular biology are providing a better understanding of the pathophysiology mechanisms of osteoporosis. One of the most significant contributions in this area was the identification of a system known as OPG (osteoprotegerin)/RANKL/ RANK (receptor activator of nuclear factor kappa B ligand), discovered in the mid-1990s. This system is responsible for skeletal health, and recent studies indicate that RANKL $\backslash$ RANK signaling also play an important role in other tissues. ${ }^{18}$

The data in this study related to the average number of patients studied showed that 477 participants were included in our study. The standard deviation was 1,357.6, and this can be explained by a great variability in the number of patients investigated in the selected studies, from 8 to 9,846 participants. We observed a lack of standardization in the concepts used and methodological differences may justify this variation. In the studies that evaluated the therapeutic response, differences found in relation to the sample size are considered extensive. ${ }^{19}$ As for duration of patient monitoring, we did not observe major differences between the studies, and those lasting two to five years $(31.8 \%)$ presented a discreet predominance over the others.

In 2007, a study conducted by Vieira et al. suggested that the effectiveness of therapeutic monitoring in the treatment of osteoporosis, carried out using the dosage of bone biomarkers, can be measured from one to three months after the beginning of the follow-up, as observed in the present study. We believe that although not standardized, the treatment time might serve as the basis for other studies given that, when bone densitometry is used, changes are observed only after one to two years. These findings can be explained through the use of qualitative ( $\mathrm{x}$-rays) or quantitative (bone densitometry, quantitative CT) $x$-ray absorption techniques, allowing the examination of the bone structure through the detection of radiopaque crystals. However, the metabolic, physiological or pathological phenomena that can affect the bone tissue, only significantly affect its radiopaque structure after a considerable period of time. Thus, the use of these techniques is limited for a more dynamic and short-term study on bone metabolism. Therefore, there is an interest in defining methodologies that can quantify substances that could represent the metabolic processes underway in the tissue. ${ }^{17}$ Studies evaluating the outcome of clinical applicability showed that $80.3 \%$ of the studies concluded that biomarkers show statistical significance with $\mathrm{p}<0.001$. The data evaluated in this study revealed the potential of bone biomarkers in clinical practice, with the most frequent indicators being: i) Control of therapeutic efficacy, ii) predicting the response in relation to adherence to treatment, iii) prediction of the risk of fracture. There are also further possibilities discussed in other articles, such as forecast bone loss and selection of patients for treatment. ${ }^{20}$ Evaluation of the control of therapeutic efficacy is believed to be the main clinical application.

According to Kerschan-Schindl et al. there was a positive correlation between early changes of biomarkers among patients under treatment and subsequent structural changes, when 1,637 post-menopausal women using teriparatide or a placebo were assessed. An increase in BAL and P1NP markers was observed in the first month in conjunction with histomorphometric indexes for $1 / 4$ computed microtomography (CT) after 22 months of treatment. ${ }^{21,22}$ When evaluating adherence to treatment, the biochemical markers of bone remodeling have been used to facilitate the monitoring of patients receiving antiresorptive therapy. It is known that bone remodeling markers decrease rapidly after the beginning of treatment (in approximately 36 months), and these markers can be useful substitutes for monitoring adherence to treatment, although data to support this hypothesis is scarce. We found a significant change of 40 and $70 \%$ reduction in bone resorption markers (serum CTX and urine NTX) 
with the use of antiresorptive medication (bisphosphonates), and a 30 to $40 \%$ reduction when catabolic agents (raloxifene) are administered. Thus, the absence of these reductions would indicate low adherence to treatment by the patient or incorrect drug administration. ${ }^{23}$ When we evaluated the prediction of risk of BMD fractures (correlated positively with bone strength), measurement using DEXA remains the best choice. Other relevant use of these biomarkers is the ability to identify women who will present a high rate of loss of bone mass during the years following menopause, in order to initiate a prevention strategy for osteoporosis. In summary, the markers of bone renewal with other demographic variables could predict around 30 to $40 \%$ of the variations of bone loss in women with untreated menopause. ${ }^{24}$ Currently the choice of treatment based on bone markers is not being applied in routine clinical practice. ${ }^{25}$ One of the limitations of this study is the small number of samples analyzed in this work, and the reduced number of national publications analyzed.

\section{Conclusion}

In recent years there has been great progress in trying to understand the use of biomarkers and their applications in osteoporosis, due to major advances in science. If we use the physiology of the bone remodeling process, the ideal markers would be those able to form the diagnosis of osteoporosis and differentiate patients classified as slow or fast losers, adding sensitivity and specificity to the bone density measurement in the fracture risk assessment, leading to more appropriate treatment, the identification of potential patients that would benefit from antiresorptive measures (fast losers or high bone turnover) or increased bone formation measures (slow losers or low bone turnover), and serving as markers for therapeutic response in order to monitor the patient's adherence to treatment. Despite new studies and tests being developed quickly and leading in this direction, up to now a series of restrictions and considerations have limited the use of biomarkers in clinical practice. However, the markers of bone remodeling have brought great advances to the knowledge of the pathophysiology of bone tissue, although different serum and urine concentrations due to characteristics that are not only biological but also analytical make it difficult to interpret the results in daily clinical practice. The articles analyzed indicate the possible applicability of these biomarkers to monitor patients, especially under treatment. Our analysis also allows us to conclude that there is no defined consensus as yet on the use of biomarkers. We believe that further research will be conducted in order to define the use of biomarkers in clinical practice, based on their potential use.

\section{Resumo}

O uso dos biomarcadores na clínica da osteoporose

A osteoporose é uma doença de caráter ascendente na população mundial. Nesse contexto, os biomarcadores ósseos vêm sendo cada vez mais estudados com o propósito de auxiliar no diagnóstico e acompanhamento desses pacientes. Os principais objetivos deste estudo incluem realizar uma revisão da literatura dos artigos cujo principal tema estudado foi a utilização dos biomarcadores de formação e degradação óssea, e avaliar uma possível aplicabilidade desses biomarcadores na prática clínica. A revisão da literatura foi realizada com artigos indexados e publicados nos últimos cinco anos, utilizando a base de dados PubMed. Os achados deste trabalho mostraram que a maioria dos artigos previamente selecionados foram publicados nos últimos dois anos, e os marcadores mais citados foram o de reabsorção óssea, o C-telopeptídeo do colágeno (CTX), que mostra maior correlação com a dinâmica do osso, e o biomarcador de formação óssea, a fosfatase alcalina específica do osso (BAP), cujos valores aumentados estão relacionados à vigência de fratura ou sugerem uma outra doença óssea. Foi observado um aumento dos artigos publicados associando os diferentes biomarcadores ósseos e uma possível aplicabilidade clínica, principalmente no controle do tratamento. As nossas conclusões sugerem que nos últimos anos houve aumento significativo das publicações avaliando o uso dos biomarcadores de remodelação óssea de formação e reabsorção e uma possível aplicabilidade clínica, principalmente na monitorização do tratamento. No entanto, acreditamos que novos estudos precisam ser conduzidos a fim de confirmar esses achados, tendo em vista as vantagens que os biomarcadores ósseos apresentam no manejo clínico da doença.

Palavras-chave: osteoporose, remodelação óssea, marcadores biológicos.

\section{References}

1. Garnero P. Bone markers in osteoporosis. Curr Osteoporos Rep. 2009; $7(3): 84-90$.

2. Eastell R, Hannon RA. Biomarkers of bone health and osteoporosis risk. Proc Nutr Soc. 2008; 67(2):157-62.

3. Martini LA, Moura EC, Santos LC, Malta DC, Pinheiro MM. Prevalência de diagnóstico auto-referido de osteoporose. Rev Saúde Pública. 2009; 43(suppl. 2):107-16. 
4. Pinheiro MM, Eis SR. Epidemiologia de fraturas pela osteoporose no Brasil: o que temos e o que precisamos. Arq Bras Endocrinol Metab. 2010; 54(2):164-70.

5. Brasil. Ministério da Saúde. Quedas de idosos. SUS gasta quase R\$ 81 milhões com fraturas em idosos em 2009. [cited 2014 Nov]. Available from: http:// www.singlecare.com.br/news/sus-gasta-quase-r\$-81-milh\%C3\%B5es-comfraturas-em-idosos-em-2009-saiba-mais!/.

6. Costa-Paiva L, Horowitz AP, Santos AO, Fonsechi-Carvasan GA, PintoNeto AM. Prevalência de osteoporose em mulheres na pós-menopausa e associação com fatores clínicos e reprodutivos. Rev Bras Ginecol Obstet. 2003; 25(7):507-12.

7. Grey A, Bolland M, Wong S, Horne A, Gamble G, Reid IR. Low-dose zoledronate in osteopenic postmenopausal women: a randomized controlled trial. J Clin Endocrinol Metab. 2012; 97(1)286-92.

8. Lee J, Vasikaran S. Current recommendations for laboratory testing and use of bone turnover markers in management of osteoporosis. Ann Lab Med. 2012; 32(2):105-12.

9. Watts NB. Clinical utility of biochemical markers of bone remodeling. Clin Chem. 1999; 45(8 Pt 2):1359-68.

10. Lenora J, Gerdhem P, Obrant KJ, Ivaska KK. Bone turnover markers are correlated with quantitative ultrasound of the calcaneus: 5-year longitudinal data. Osteoporos Int. 2009; 20(7):1225-32

11. Heaney RP. Pathophysiology of osteoporosis. Endocrinol Metab Clin North Am. 1998; 27(2):255-65.

12. Grey A, Bolland M, Wong S, Horne A, G Gamble, Reid IR. Low-dose zoledronate in osteopenic postmenopausal women: a randomized controlled trial. J Clin Endocrinol Metab. 2012; 97(1):286-92 .

13. Borges JLC, Freitas A, Bilezikian JP. Accelerated fracture healing with teriparatide. Arq Bras Endocrinol Metab. 2013; 57(2):153-6.

14. Jakob F, Oertel H, Langdahl B, Ljunggren O, Barrett A, Karras D, et al. Effects of teriparatide in postmenopausal women with osteoporosis pre-treated with bisphosphonates: 36-month results from the European Forsteo Observational Study. Eur J Endocrinol. 2012; 166(1):87-97.

15. Vasikaran S, Eastell R, Bruyère $O$, Foldes AJ, Garnero $P$, Griesmacher A, et al.; IOF-IFCC Bone Marker Standards Working Group. Markers of bone turnover for the prediction of fracture risk and monitoring of osteoporosis treatment: a need for international reference standards. Osteoporos Int. $2011 ; 22(2): 391-420$

16. Vasikaran SD, Cooper C, Kanis JA. Recommendations for bone marker standards in osteoporosis: what, why and where to now? Ann Clin Biochem. 2011; 48(Pt2):91-2.

17. Vieira JGH. Diagnóstico laboratorial e monitoramento das doenças osteometabólicas. J Bras Patol Med Lab. 2007; 43(2):75-82.

18. Boyce BF, Xing L. Biology of RANK, RANKL, and osteoprotegerin. Arthritis Res Ther. 2007; 9(Suppl 1):S1.

19. Kuno R, Roquetti MH, Gouveia N. [Concepts and determination of reference values for human biomonitoring of environmental contaminants]. Rev Panam Salud Publica. 2010; 27(1):74-9.

20. Vasikaran SD, Glendenning P, Morris HA. The role of biochemical markers of bone turnover in osteoporosis management in clinical practice. Clin Biochem Rev. 2006; 27(3):119-21.

21. Kerschan-Schindl K, Mikosch P, Obermayer-Pietsch B, Gasser RW, Dimai HP, Fahrleitner-Pammer A, et al. Current controversies in clinical management of postmenopausal osteoporosis. Exp Clin Endocrinol Diabetes. 2014; 122(8):437-44.

22. Schafer AL, Vittinghoff E, Ramachandran R, Mahmoudi N, Bauer DC. Laboratory reproducibility of biochemical markers of bone turnover in clinical practice. Osteoporos Int. 2010;21(3):439-45.

23. Garnero P, Shih WJ, Gineyts E, Karpf DB, Delmas PD. Comparison of new biochemical markers of bone turnover in late postmenopausal osteoporotic women in response to alendronate treatment. J Clin Endocrinol Metab. 1994; 79(6):1693-700.

24. Vasikaran SD, Cooper C, Kanis, JA. Recommendations for bone marker standards in osteoporosis: what, why and where to now? Ann Clin Biochem. 2011; 48(Pt 2):91-2.

25. Chesnut CH 3rd, Bell NH, Clark GS, Drinkwater BL, English SC, Johnson $\mathrm{CC} \mathrm{Jr}$, et al. Hormone replacement therapy in postmenopausal women: urinary n-telopeptide of type I collagen monitors therapeutic effect and predicts response of bone mineral density. Am J Med. 1997; 102(1):29-37.

26. Romero Barco CM, Manrique Arija S, Rodríguez Pérez M. Biochemical markers in osteoporosis: usefulness in clinical practice. Reumatol Clin. 2012; 8(3):149-52. 